\title{
Influence of adenosine on preservation of porcine pancreas in islet transplantation
}

\author{
W.Q. Song, D.Z. Fu, Y. Cheng and Y.F. Liu \\ Department of General Surgery, The First Hospital of China Medical University, \\ Shenyang, China \\ Corresponding author: Y.-F. Liu \\ E-mail: yongfengliumed@yeah.net \\ Genet. Mol. Res. 14 (4): 18293-18301 (2015) \\ Received August 10, 2015 \\ Accepted October 15, 2015 \\ Published December 23, 2015 \\ DOI http://dx.doi.org/10.4238/2015.December.23.17
}

\begin{abstract}
Ischemia time during transplantation has greatly restricted the quality and utilization of grafts. To improve the quality of islet transplantation, adenosine was added into the University of Wisconsin (UW) pancreas perfusate to assess its effect on islet yield and function in porcine pancreas. Ten pancreata from donation after cardiac death pigs were obtained and randomly divided into two groups: control group $(\mathrm{N}=5)$ with UW perfusion solution, and experimental group $(\mathrm{N}=5)$ with adenosine-enriched UW perfusion solution. The yield and purity of the islet cells were counted after they were collected, purified, and stained with dithizone. Acridine orange/propidium iodide staining was applied to determine islet cell viability. Islet function was assessed by glucose stimulated insulin secretion assays, and released insulin was quantified by enzyme-linked immunosorbent assay. The metabolic substrates of the pancreas were analyzed by trace dialysis technology. We found that the addition of adenosine in UW perfusion solution significantly increased the yield, purity and viability of islet cells, as well as enhanced their insulin release. In addition, the levels of metabolic substrates, pyruvate and lactate, were significantly reduced. The addition of adenosine could effectively increase islet cell viability during mechanical perfusions,
\end{abstract}


which may improve islet transplantation. This perfusion protocol may be clinically feasible, and should be considered in the clinical setting.

Key words: Adenosine; Organ donation; Hypothermic mechanical perfusion; Islet transplantation

\section{INTRODUCTION}

Diabetes has become a serious threat to human health amongst the other major public health problems, and its prevalence is increasing every year (Bruni et al., 2014). With new advancements in medical technologies, pancreatic islet transplantation has become an effective means for the treatment of diabetes (llkova et al., 1997; Robertson et al., 1999; Khairoun et al., 2013). However, one major limitation to clinical islet transplantation is the availability of donor organs. Donation after cardiac death (DCD) (Ray et al., 2009), defined as the irreversible cessation of circulatory and respiratory functions, has become an internationally recognized organ source.

The quantity and activity of isolated islet cells have been documented as major determinants for successful islet transplantations. Therefore, the procurement and preservation of viable islets is critical. Hypothermic machine perfusion is an excellent preservation method that has been widely used in the field of organ transplantation (Taylor et al., 2008; Taylor and Baicu, 2010). Extensive studies revealed that hypothermic machine perfusion could maintain organ function, prevent ischemic injury, and improve transplant survival rates (Iwanaga et al., 2008; Moers et al., 2009; Karcz et al., 2010; Taylor et al., 2010). University of Wisconsin (UW) solution is the most commonly used perfusate, which contains a phosphate buffer, high potassium, and oxygen radical scavengers (Schneeberger et al., 2009). However, increasing evidence has suggested that it may be a suboptimal solution for pancreas preservation (Tsujimura et al., 2003; Matsumoto et al., 2004).

Adenosine, as an endogenous nucleoside, is an important metabolic intermediate. Adenosine has a wide range of functions in the body via interactions with special adenosine receptors located on the cell surface. Previous studies have shown that adenosine could trigger or mediate the ischemia preconditioning phenomenon (Osswald and Gleiter, 1993; Nilsson et al., 2000), and prolong cardiac storage (Galiñanes and Hearse, 1992; Fremes et al., 1995). A recent report has also shown that adenosine plays an important role in the regeneration of pancreatic $\beta$-cells (Andersson et al., 2012). Additionally, adenosine could stimulate adenosine triphosphate (ATP) synthesis after perfusion to restore high energy phosphates in the graft (Mentzer et al., 1993).

In the present study, we aim to evaluate the effects of adenosine on islet quality during mechanical perfusion. DCD donors from Duroc-Landrace-Large White ternary hybrid pigs were chosen as research subjects. Preservation of pancreas was achieved using either adenosineenriched UW solution or UW solution alone prior to islet isolation. The islet yield, purity, activity, and insulin release index between the control (UW solution only) and experimental group (adenosineenriched UW solution) were compared at optimal perfusion times.

\section{MATERIAL AND METHODS}

\section{Materials and process}

Ten DCD porcine pancreata were obtained from Duroc-Landrace-Large White ternary hybrid pigs weighing $25 \pm 3 \mathrm{~kg}$ from Shenyang Agricultural University. The pancreata were 
randomly divided into two groups. The control group was mechanically perfused with UW solution (Bristol-Myerse Squibb, New York, NY, USA), whereas the experimental group was perfused with adenosine-enriched (Sigma, St. Louis, MO, USA) UW solution. The mechanical perfusion time was set at $180 \mathrm{~min}$, which was determined as the optimal perfusion time in our previous studies. All animal procedures were approved by the animal research ethics committee of the source institution.

\section{Preparation of the DCD porcine model}

Compound anesthesia method was performed: Sumianxin II $(0.1 \mathrm{~mL} / \mathrm{kg})$ combined with propofol (2 $\mathrm{mg} / \mathrm{kg}$ ) was used to induce anesthesia. Anesthesia was maintained via continuous infusion of propofol and rocuronium after endotracheal intubation and artificial ventilation. All animals were maintained under standardized and controlled conditions during the operation: tidal volume was $10 \mathrm{~mL} / \mathrm{kg}$, respiratory frequency was 15 times per min, body center temperature was $37.8^{\circ}$ to $38.3^{\circ} \mathrm{C}$, and peak inspiratory pressure (PIP) was less than $25 \mathrm{~cm} \mathrm{H}_{2} \mathrm{O}$. The breathing machine was removed when the pigs were in deep anesthesia. DCD was induced by a sharp reduction in $\mathrm{PaO}_{2}$ followed by gradual increase in $\mathrm{PaCO}_{2}$, resulting in hypercapnia and decrease in arterial $\mathrm{pH}$. Responsiveness hypertension and bradycardia appeared subsequently, finally leading to cardiac arrest. The average death time was $19.25 \mathrm{~min}$.

\section{Acquisition of DCD porcine pancreas and mechanical perfusion}

After declaration of cardiac death, the abdomen was opened by median laparotomy. Abdominal aorta sleeves were connected with the infusion pump head to ensure that gastroduodenal, splenic and superior mesenteric arteries were effectively perfused during the procedure. The temperature of perfusion fluid was maintained at 0 to $4^{\circ} \mathrm{C}$. The perfusion pressure was maintained at less than 10 $\mathrm{mmHg}$ during the first $60 \mathrm{~min}$ to reduce micro artery damage, and was subsequently adjusted to 10 to $30 \mathrm{mmHg}$ according to the perfusion parameters. The mechanical perfusion time was $180 \mathrm{~min}$ in total.

\section{Separation and purification of DCD porcine islet}

The method improved by Minnesota University (Gürol et al., 2004) was used to isolate and purify the islet of Langerhans. Cold collagenase solution $(1.5 \mathrm{mg} / \mathrm{mL})$ prepared with Hank's liquid was retrogradely injected into the pancreatic duct at a rate of 3 to $4 \mathrm{~mL} / \mathrm{min}$ after the pancreas was put into a $50-\mathrm{mL}$ centrifuge tube. The tube was subjected to heat shock for $25 \mathrm{~min}$ in the water bath at $37^{\circ} \mathrm{C}$, and $1 \mathrm{M} \mathrm{NaOH}$ solution was added to maintain the digestive fluid under a pH of $7.8 \pm 1$. The digestion process was terminated using cold Hank's liquid when the pancreas appeared as a fine granular solution, and the islets were collected.

The islets were purified by discontinuous density gradient centrifugation. Islet suspensions were collected at the junctions of 23 and 20.5 , and $20.5 \%$ and $11 \%$ Ficoll gradient. The suspension was rinsed (1000 rpm, 4 to $8^{\circ} \mathrm{C}, 3 \mathrm{~min}$ ) and cultured with RPMI-1640 for further experimentation.

\section{Detection of DCD pig islets}

\section{Calculation of islet equivalents and islet purity}

Islet cells were stained with dithizone (DTZ) (Shiroi et al., 2002), and the positively labeled 
cells were counted. Islet cells with a diameter of $150 \mu \mathrm{m}$ were considered as one islet equivalent (IEQ). The experiment was performed in triplicates using a $50 \mu \mathrm{L}$ mixture each time. IEQ was calculated as follows:

$$
\mathrm{N}=\mathrm{A} \times 20 \times \mathrm{V} \quad \text { Equation } 1
$$

where $\mathrm{N}$ indicates the number of islet equivalents, $\mathrm{A}$ indicates the average number of DTZ- positive cells, and $\mathrm{V}$ indicates the total sample volume $(\mathrm{mL})$.

The purity of islet cells was calculated as the percentage of islet cells in all endocrine and exocrine cells.

\section{Islet viability}

Islet viability was revealed by acridine orange/propidiun iodide ( $\mathrm{AO} / \mathrm{PI})$ staining. The $\mathrm{AO} / \mathrm{PI}$ solution was mixed with islet suspension for $10 \mathrm{~min}$ on a watch glass. The watch glass was then observed under the fluorescence microscope. Viability of islet cells was calculated as follows:

Cell viability $=$ total number of living cells $/($ total number cells $) \times 100 \% \quad$ Equation 2

\section{Detection of insulin and metabolic products of the pancreas}

Islet function was evaluated by static glucose stimulated secretion assays, and secreted insulin was measured using enzyme-linked immunosorbent assay (ELISA). A total of 10 IEQ were counted and incubated in Kreb's-Hank's solution (contains $10 \mathrm{mM}$ HEPES and $0.25 \%$ BSA) with low glucose $(2.8 \mathrm{mM})$ for $2 \mathrm{~h}$, followed by high glucose $(16.7 \mathrm{mM})$ for $1 \mathrm{~h}$. Culture media was collected to detect the insulin levels at 2 and $3 \mathrm{~h}$. The insulin release index was calculated as follows:

Insulin release index $=$ insulin content at $3 \mathrm{~h}$ (high glucose medium) $/$ insulin content at $2 \mathrm{~h}$ (low glucose medium)

Equation 3

The metabolic products of the pancreas were analyzed by trace dialysis technology (Wælgaard et al., 2008; Kannerup et al., 2009) to evaluate ischemia reperfusion damage after the addition of adenosine.

\section{Statistical analysis}

Results are expressed as mean \pm standard deviation (SD). All data were analyzed using the SPSS 19.0 software. Results with $\mathrm{P}<0.05$ were considered statistically significant.

\section{RESULTS}

\section{Detection of islet yield and purity}

A number of islet cell groups and individual cells with circular or ovoid shapes were observed under the microscope. DTZ-positive cells appeared scarlet with smooth and opaque 
surfaces. More positively stained cells were observed in the experimental group as compared with the control group (Figure 1A, B). Exocrine cells were also observed, which were negative for DTZ. The number of islet cells in the control group was $3172 \pm 503$, while the experimental group had a significant increase in the number of islet cells, $3816 \pm 522$ (Figure 1C). Furthermore, islet purity was also significantly increased in the adenosine-enriched group (Figure 2).
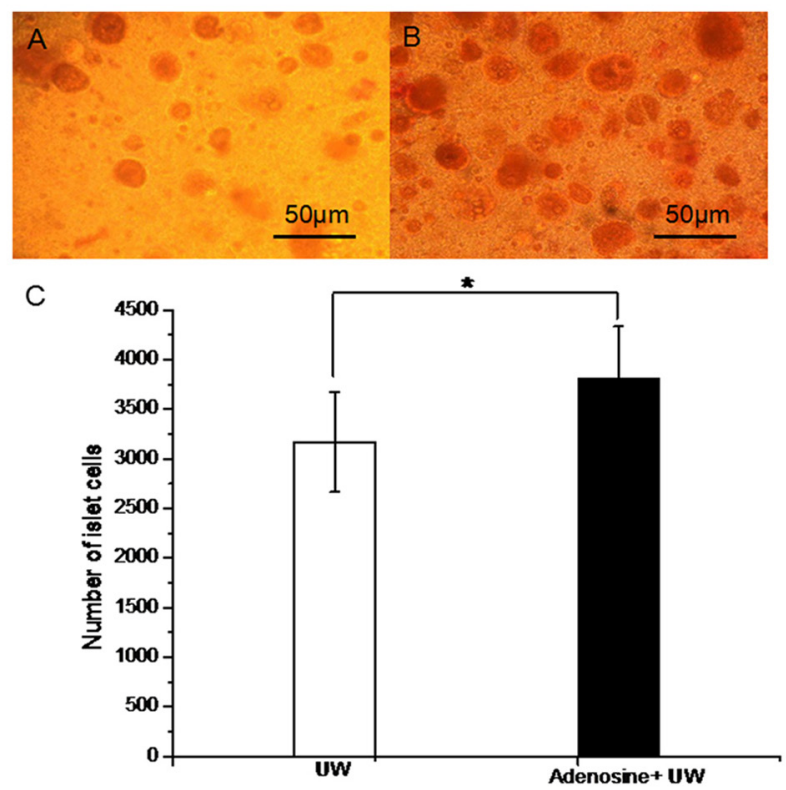

Figure 1. DTZ staining and islet cells yields with different perfusates. A. Staining of control group (UW perfusion solution) islet cells with DTZ. B. Staining of experimental group (UW + adenosine perfusion solution) islet cells with DTZ. C. Islet cell yields in the two groups. Magnification of A and B: $200 X .{ }^{*} P<0.05$.

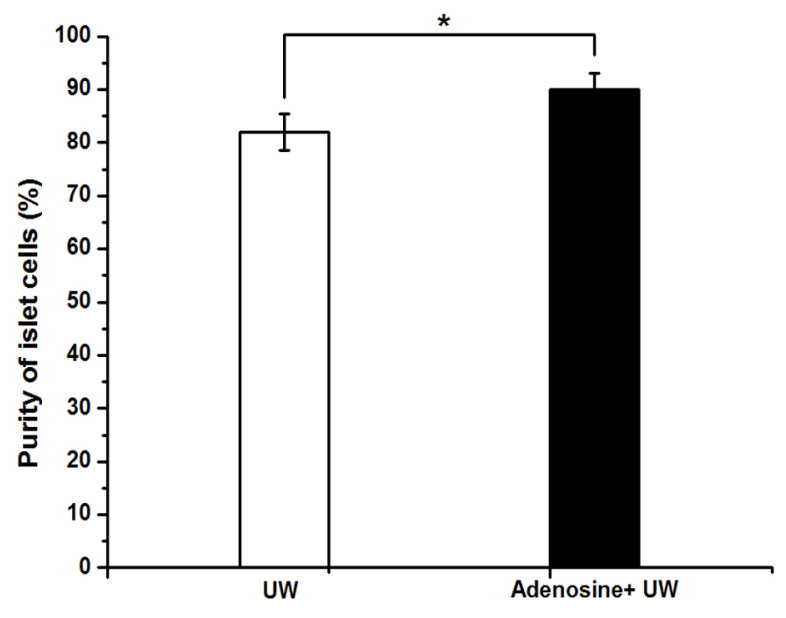

Figure 2. Islet cell purity with different perfusates. ${ }^{*} \mathrm{P}<0.05$ between groups. 


\section{Evaluation of islet cell viability}

AO/PI fluorescence staining was used to detect cell viability and growth status under different perfusion environments. Cell density in the UW group was lower than that in the adenosineenriched UW group, and the sizes of cells in the latter group were also more uniform. The majority of islet cells were positively stained by $\mathrm{AO}$, as demonstrated by strong green fluorescence in both groups. Only very few cells were dead, and expressed red fluorescence following $\mathrm{PI}$ staining (Figure 3A, B). The experimental group showed significantly higher cell viability as compared with the control group (Figure $3 \mathrm{C}$ ).

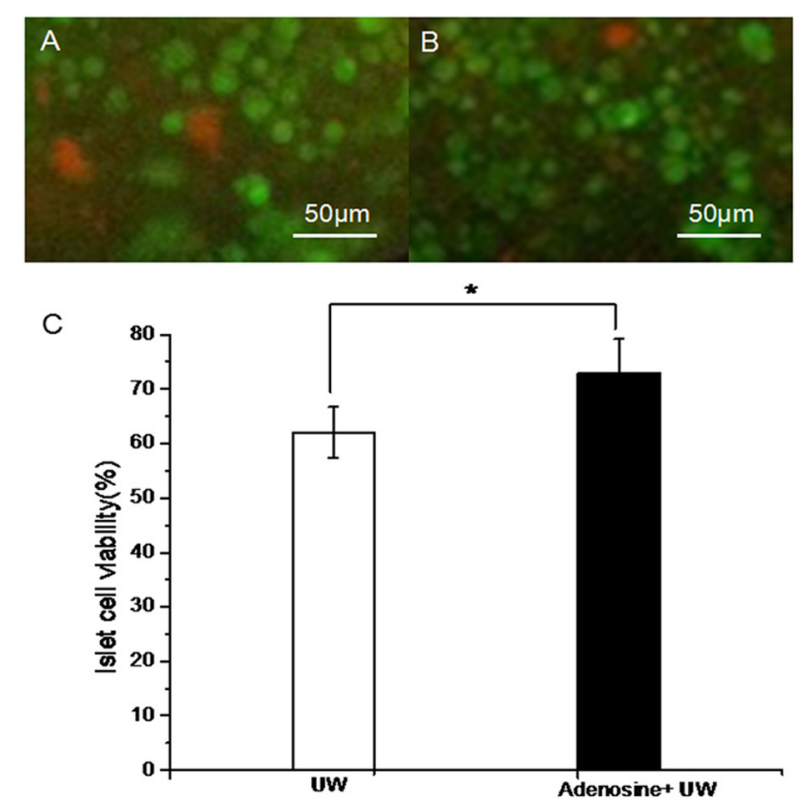

Figure 3. AO/PI staining and islet cell viability with different perfusates. A. AO/PI staining of control group islet cells. B. AO/PI staining of experimental group islet cells. C. Islet cell viability in the control and experimental groups. Green fluorescence $(\mathrm{AO})$ represents living cells; and red fluorescent $(\mathrm{PI})$ represents necrotic dead cells. Magnification of $\mathrm{A}$ and B: $200 X .{ }^{*} P<0.05$.

\section{Insulin release index}

The level and index of insulin release are shown in Table 1. Results show that insulin release in the adenosine-enriched group was lower compared to that in the UW group when stimulated with low glucose. However, under high glucose conditions, insulin secreted by the adenosine-enriched group was significantly higher as compared to that by the UW group ( $P<$ 0.05). This finding suggests that adenosine may inhibit cytokine damage to islet cells.

\section{Detection of pancreatic metabolites in different perfusion groups}

Results indicate that the total amount of glucose, triglycerides, and glutamic acid in the 
adenosine-enriched group were comparable with that of the UW group (Table 2), while lactate and pyruvate salt were significantly decreased $(P<0.05)$ (Figure 4$)$. This suggests that adenosine may reduce ischemia reperfusion damage to cell membranes as well as other organelles.

Table 1. Insulin secretion and release index with different perfusates.

\begin{tabular}{lcrr}
\hline & \multicolumn{2}{c}{ Release quantity of insulin $(\mu \mathrm{lU} / \mathrm{mL})$} & Release index of insulin \\
\cline { 2 - 4 } & Low sugar stimulus & High sugar stimulus & $2.81 \pm 0.17^{*}$ \\
\hline UW solution & $301.9 \pm 26.1$ & $850 \pm 119.5$ & $3.18 \pm 0.21^{*}$ \\
\hline
\end{tabular}

${ }^{*} \mathrm{P}<0.05$

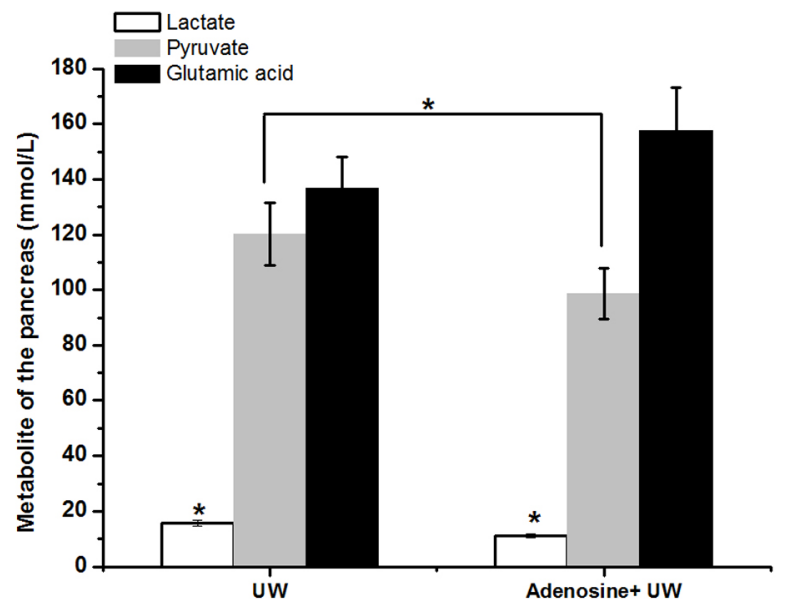

Figure 4. Lactate, pyruvate, and glutamic acid in control and experimental groups. ${ }^{*} \mathrm{P}<0.05$ between groups.

Table 2. Pancreatic metabolites with different perfusates.

\begin{tabular}{lcc}
\hline & UW solution & Adenosine + UW \\
\hline Glucose $(\mathrm{mM})$ & $0.139 \pm 0.009$ & $0.158 \pm 0.014$ \\
Lactate $(\mathrm{mM})$ & $15.7 \pm 1.0^{*}$ & $11.2 \pm 0.6^{*}$ \\
Pyruvate $(\mathrm{mM})$ & $120.2 \pm 11.3^{*}$ & $98.6 \pm 9.1^{*}$ \\
Triacylglycerol $(\mathrm{mg} / \mathrm{dL})$ & $112.3 \pm 15.8$ & $115.6 \pm 21.1$ \\
Glutamic acid $(\mathrm{mM})$ & $136.8 \pm 11.3$ & $157.5 \pm 15.7$ \\
\hline
\end{tabular}

${ }^{*} \mathrm{P}<0.05$.

\section{DISCUSSION}

The incidence of diabetes is continuous, which has serious implications for public health (Green et al., 1992). The current methods for treatment of diabetes mainly include insulin injection, insulin pump, whole pancreas transplantation, and islet cell transplantation (Sutherland et al., 2001; Pickup et al., 2002; Robertson, 2004). With the maturation of islet purification technology, islet transplantation as a diabetes therapy has achieved gratifying results. However, many technical problems still exist, such as the shortage of organ donors and the challenges in in vitro organ preservation. 
The hypothermic mechanical perfusion technique has become widely used in organ transplantation (Jensen et al., 1987). Morino et al. (1992) suggested that transplanted organs respond to ischemic injury with increased catabolism, and that a lower temperature could reduce islet metabolism and catabolism, thereby maintaining its function and survival. Mechanical perfusion can also continuously remove existing metabolic wastes, and provide oxygen and other necessary matrices for the transplantation procedure (Guarrera et al., 2005). On the other hand, it may also cause toxicity to the organs, as mitochondria and other organelles may not be able to function well under lower temperatures, leading to changes in enzyme activities and RNA transcription.

The effect of adenosine on the function of DCD porcine pancreatic islet was explored in this study. Adenosine was added to the UW solution during hypothermic mechanical perfusion of the pancreas. The addition of adenosine significantly increased the yield, viability, and purity of islet cells. In addition, the production of insulin was also significantly enhanced. Previous studies have indicated that adenosine may enter the myocardium via phosphorylation, and generate adenosines that participate in myocardial energy metabolism, expansion of coronary blood vessels and increase in blood flow (Berne, 1980; Mustafa et al., 2009). Mentzer et al. (1993) also revealed that adenosine could stimulate ATP synthesis after reperfusion of the graft. Additionally, adenosine was reported to prevent cell damage by inhibiting $\mathrm{K}^{+}$- induced intracellular $\mathrm{Ca}^{2+}$ loading (Jovanović et al., 1998). Unsurprisingly, in the present study, the combination of adenosine and UW solution could effectively promote islet cell metabolism, reduce pyruvate and lactate contents, and mitigate damages to cell membranes, lysosomes and mitochondria.

In conclusion, our experimental results confirmed that addition of adenosine into the UW solution during hypothermic mechanical perfusion could effectively improve islet cell yield, viability, and metabolic activity as well as protect islet function. This procurement protocol may be clinically feasible and should be considered in the clinical setting.

\section{Conflicts of interest}

The authors declare no conflict of interest.

\section{ACKONWLEDGMENTS}

Research received no specific grants from any funding agency in public, commercial, or not-for-profit sectors.

\section{REFERENCES}

Andersson O, Adams BA, Yoo D, Ellis GC, et al. (2012). Adenosine signaling promotes regeneration of pancreatic $\beta$ cells in vivo. Cell Metab. 15: 885-894.

Berne RM (1980). The role of adenosine in the regulation of coronary blood flow. Circ. Res. 47: 807-813.

Bruni A, Gala-Lopez B, Pepper AR, Abualhassan NS, et al. (2014). Islet cell transplantation for the treatment of type 1 diabetes: recent advances and future challenges. Diabetes Metab. Syndr. Obes. Targets Ther. 7: 211-223.

Fremes SE, Zhang J, Furukawa RD, Mickle DA, et al. (1995). Adenosine pretreatment for prolonged cardiac storage. An evaluation with St. Thomas' Hospital and University of Wisconsin solutions. J. Thorac. Cardiovasc. Surg. 110: $293-301$.

Galiñanes M and Hearse DJ (1992). Exogenous adenosine accelerates recovery of cardiac function and improves coronary flow after long-term hypothermic storage and transplantation. J. Thorac. Cardiovasc. Surg. 104: 151-158.

Green A, Andersen PK, Svendsen AJ and Mortensen K (1992). Increasing incidence of early onset type 1 (insulin-dependent) diabetes mellitus: a study of Danish male birth cohorts. Diabetologia 35: 178-182.

Guarrera JV, Estevez J, Boykin J, Boyce R, et al. (2005). Hypothermic machine perfusion of liver grafts for transplantation: technical development in human discard and miniature swine models. Transplant. Proc. 37: 323-325. 
Gürol AO, Yillar G, Kursun AO, Kücük M, et al. (2004). A modified automated method for isolation of viable pancreatic islets in laboratory animals. Transplant. Proc. 36: 1526-1527.

Ilkova H, Glaser B, Tunçkale A, Bagriaçik N, et al. (1997). Induction of long-term glycemic control in newly diagnosed type 2 diabetic patients by transient intensive insulin treatment. Diabetes Care 20: 1353-1356.

Iwanaga Y, Sutherland DE, Harmon JV and Papas KK (2008). Pancreas preservation for pancreas and islet transplantation. Curr. Opin. Organ Transplant. 13: 445-451.

Jensen S, Sørensen T and Zimmer J (1987). Cryopreservation of fetal rat brain tissue later used for intracerebral transplantation. Cryobiology 24: 120-134.

Jovanović A, Lopez JR, Alekseev AE, Shen WK, et al. (1998). Adenosine prevents $\mathrm{K}^{+-}$induced $\mathrm{Ca}^{2+}$ loading: insight into cardioprotection during cardioplegia. Ann. Thorac. Surg. 65: 586-591.

Kannerup AS, Grønbæk H, Funch-Jensen P, Jørgensen RL, et al. (2009). The influence of preconditioning on metabolic changes in the pig liver before, during, and after warm liver ischemia measured by microdialysis. Hepatol. Int. 3: 310-315.

Karcz M, Cook HT, Sibbons P, Gray C, et al. (2010). An ex-vivo model for hypothermic pulsatile perfusion of porcine pancreata: hemodynamic and morphologic characteristics. Exp. Clin. Transplant. 8: 55-60.

Khairoun M, de Koning EJ, van den Berg BM, Lievers E, et al. (2013). Microvascular damage in type 1 diabetic patients is reversed in the first year after simultaneous pancreas-kidney transplantation. Am. J. Transplant. 13: 1272-1281.

Matsumoto S, Zhang G, Qualley S, Clever J, et al. (2004). The effect of two-layer (University of Wisconsin solution/ perfluorochemical) preservation method on clinical grade pancreata prior to islet isolation and transplantation. Transplant. Proc. 36: 1037-1039.

Mentzer RM Jr, Bünger R and Lasley RD (1993). Adenosine enhanced preservation of myocardial function and energetics. Possible involvement of the adenosine A1 receptor system. Cardiovasc. Res. 27: 28-35.

Moers C, Smits JM, Maathuis MH, Treckmann J, et al. (2009). Machine perfusion or cold storage in deceased-donor kidney transplantation. N. Engl. J. Med. 360: 7-19.

Morino M, Adam R, Diamond T, Castaing D, et al. (1992). Effect of storage temperature on early graft function following liver transplantation. Clin. Transplant. 6: 97-99.

Mustafa SJ, Morrison RR, Teng B and Pelleg A (2009). Adenosine receptors and the heart: role in regulation of coronary blood flow and cardiac electrophysiology. Handb. Exp. Pharmacol. 193: 161-188.

Nilsson B, Friman S, Wallin M, Gustafsson B, et al. (2000). The liver protective effect of ischemic preconditioning may be mediated by adenosine. Transplant Int. 13 (Suppl 1): S558-S561.

Osswald $\mathrm{H}$ and Gleiter C (1993). Renal effects of adenosine: possible consequences for kidney transplantation. Zentralbl. Chir. 118: 90-102.

Pickup J, Mattock M and Kerry S (2002). Glycaemic control with continuous subcutaneous insulin infusion compared with intensive insulin injections in patients with type 1 diabetes: meta-analysis of randomised controlled trials. BMJ 324: 705.

Ray C, Kanwar A, Noormohamed MS, Sohrabi S, et al. (2009). Securing the aorta for organ perfusion in donation after cardiac death donors; novel techniques and a cautionary tale. Transplant Int. 22: 856-857.

Robertson RP (2004). Islet transplantation as a treatment for diabetes - a work in progress. N. Engl. J. Med. 350: 694-705.

Robertson RP, Sutherland DE and Lanz KJ (1999). Normoglycemia and preserved insulin secretory reserve in diabetic patients 10-18 years after pancreas transplantation. Diabetes 48: 1737-1740.

Schneeberger S, Biebl M, Steurer W, Hesse UJ, et al. (2009). A prospective randomized multicenter trial comparing histidinetryptophane-ketoglutarate versus University of Wisconsin perfusion solution in clinical pancreas transplantation. Transplant Int. 22: 217-224.

Shiroi A, Yoshikawa M, Yokota H, Fukui H, et al. (2002). Identification of insulin-producing cells derived from embryonic stem cells by zinc-chelating dithizone. Stem Cells 20: 284-292.

Sutherland DE, Gruessner RW and Gruessner AC (2001). Pancreas transplantation for treatment of diabetes mellitus. World J. Surg. 25: 487-496.

Taylor MJ and Baicu SC (2010). Current state of hypothermic machine perfusion preservation of organs: The clinical perspective. Cryobiology 60 (Suppl 3): S20-S35.

Taylor MJ, Baicu S, Leman B, Greene E, et al. (2008). Twenty-four hour hypothermic machine perfusion preservation of porcine pancreas facilitates processing for islet isolation. Transplant. Proc. 40: 480-482.

Taylor MJ, Baicu S, Greene E, Vazquez A, et al. (2010). Islet isolation from juvenile porcine pancreas after 24-h hypothermic machine perfusion preservation. Cell Transplant. 19: 613-628.

Tsujimura T, Kuroda Y, Avila JG, Kin T, et al. (2003). Resuscitation of the ischemically damaged human pancreas by the twolayer method prior to islet isolation. Transplant. Proc. 35: 2461-2462.

Wælgaard L, Thorgersen EB, Line PD, Foss A, et al. (2008). Microdialysis monitoring of liver grafts by metabolic parameters, cytokine production, and complement activation. Transplantation 86: 1096-1103. 